\title{
Science
}

March 2012, Vol. 335 (6072), pp. 1045-1047

http://dx.doi.org/10.1126/science.1214594

Archimer

(c) 2012 American Association for the Advancement of

Science. All Rights Reserved.

\section{Reconsidering the Consequences of Selective Fisheries}

\author{
S. M. Garcia ${ }^{1,{ }^{*}}$, J. Kolding ${ }^{1,2}$, J. Rice ${ }^{1,3}$, M.-J. Rochet $^{4}{ }^{*}$, S. Zhou ${ }^{5}$, T. Arimoto ${ }^{6}$, J. E. Beyer ${ }^{7}$, L. \\ Borges $^{8}$, A. Bundy ${ }^{9}$, D. Dunn ${ }^{10}$, E. A. Fulton ${ }^{11}$, M. Hall ${ }^{12}$, M. Heino ${ }^{2,13,14}$, R. Law ${ }^{15}$ M. Makino ${ }^{1}, 16$, \\ A. D. Rijnsdorp ${ }^{17}$, F. Simard ${ }^{18}$, A. D. M. Smith ${ }^{11}$
}

${ }^{1}$ Commission on Ecosystem Management, International Union for Conservation of Nature (IUCNCEM), Fisheries Expert Group, 1000 Brussels, Belgium.

${ }^{2}$ Department of Biology, University of Bergen, 5020 Bergen, Norway.

${ }^{3}$ Fisheries and Oceans, Ottawa, Ontario K1A OE6, Canada.

${ }^{4}$ L'Institut Francais de Recherche pour l'Exploitation de la Mer (IFREMER), 44300 Nantes, France.

${ }^{5}$ CSIRO Marine and Atmospheric Research, Brisbane, Queensland 4001, Australia.

${ }^{6}$ Tokyo University of Marine Science and Technology, Tokyo 108-8477, Japan.

7 Danish National Institute of Aquatic Resources (DTU Aqua), Charlottenlund Castle, 2920, Denmark.

${ }^{8}$ FishFix, Brussels, Belgium.

${ }^{9}$ Bedford Institute of Oceanography, Dartmouth, Nova Scotia B3B 1A5, Canada.

${ }^{10}$ Duke University Marine Geospatial Ecology Lab, Beaufort, NC 28516, USA.

${ }^{11}$ CSIRO Marine and Atmospheric Research, Hobart, Tasmania 7000, Australia.

${ }^{12}$ Inter-American Tropical Tuna Commission, La Jolla, CA 92037, USA.

${ }^{13}$ Institute of Marine Research, 5005 Bergen, Norway.

${ }^{14}$ International Institute for Applied Systems Analysis, 2361 Laxenburg, Austria.

${ }^{15}$ Biology Department, University of York, York YO10 5DD, UK.

${ }^{16}$ Fisheries Research Agency, Yokohama, 220-6115, Japan.

${ }^{17}$ Institute for Marine Resources and Ecosystem Studies (IMARES), 1976 IJmuiden, Netherlands.

${ }^{18}$ Global Marine Programme, IUCN, 1196 Gland, Switzerland.e

*: Corresponding author : M.-J. Rochet, email address: Marie.Joelle.Rochet@ifremer.fr

\begin{abstract}
:
Concern about the impact of fishing on ecosystems and fisheries production is increasing $(1,2)$. Strategies to reduce these impacts while addressing the growing need for food security (3) include increasing selectivity $(1,2)$ : capturing species, sexes, and sizes in proportions that differ from their occurrence in the ecosystem. Increasing evidence suggests that more selective fishing neither maximizes production nor minimizes impacts (4-7). Balanced harvesting would more effectively mitigate adverse ecological effects of fishing while supporting sustainable fisheries. This strategy, which challenges present management paradigms, distributes a moderate mortality from fishing across the widest possible range of species, stocks, and sizes in an ecosystem, in proportion to their natural productivity (8), so that the relative size and species composition is maintained.
\end{abstract}




\section{Selectivity: Rationale, Undesirable Effects}

Fishers select species and sizes for various practical, economic, and regulatory reasons. The idea of increasing sizeselectivity to increase yields is centuries old (9). The concept of growth overfishing (loss of yield when small fish are caught) has been a cornerstone of modern fisheries management since the 1950s (10). Avoiding juveniles has been justified to let fish reproduce at least once before they are harvested (11). Protecting rare and charismatic species has also gained currency (12). New guidelines from the United Nations Food and Agriculture Organization (FAO) reiterate the objective of "minimizing the capture and mortality of species and sizes which are not going to be used", i.e., bycatch (13). Fisheries worldwide have used species and size limits $(9,14)$, gear technology $(5,15)$, and spatial and temporal fishing restrictions $(16)$ to reduce fishing impacts while pursuing human benefits.

But selective removals will inevitably alter the composition of a population or community and, consequently, ecosystem structure and biodiversity. Old individuals contribute the most to reproduction (17). Even moderate fishing reduces the proportion of large and old fish in a population. Selectively fishing large individuals amplifies this effect, and although it does not provide the expected yield benefits (9), it results in ecological and evolutionary side effects. Removal of older age classes can increase fluctuations in population abundance (18), which, in turn, increase the risks associated with low abundance. Increased and selective fishing has been predicted to drive stocks toward earlier maturation and smaller adult body size (19). Such changes appear common (20), although their environmental and genetic causes are not fully disentangled (21).

Community effects of heavy, selective exploitation include alteration of trophic structure on the Eastern Scotian Shelf (6), and a shift from large- to smaller-sized species and individuals in the North Sea (22) (fig. S1). By contrast, in several African small-scale inland fisheries, the fish size spectrum (23) has been maintained under intense and diverse fishing activities that cause high mortality with low selectivity $(5,24)$ (fig. S1).

Results from models suggest that moderating fishing mortality across a wide range of species and sizes maximizes overall catch summed across species while better conserving biodiversity. Multispecies fishery models show that increased mesh sizes may reduce total yield, owing to increased predation by large fish (25), and that targeting a limited range of species or sizes will not maximize diversity at most fishing mortalities (26). In size-based models, depletion of particular sizes by fishing affects smaller-size groups, because their predation mortality is reduced, and larger-size groups by both reduced food for predators of the harvested sizes and faster growth rates of the survivors of the selective fishing. This causes destabilizing fluctuations in biomass that are wider when the size range fished is narrower and/or the sizes fished are large (27). When models allow for some diversity in properties other than size within size classes, fluctuations persist but are dampened (28).

Synthesizing across ecosystem models from 30 systems (see SOM for details) suggests that the biodiversity benefits from selective fishing occur only at fishing mortalities so low that yield is not economically sustainable (see the graph) (fig. S2). With fishing spread over more groups and sizes, yields are higher and impacts of fishing — such as population extirpations (local extinctions) and biomass depletion—are lower across a broad range of fishing mortalities. 


\section{Toward Balanced Harvesting}

The conventional "increased selectivity" paradigm may be inconsistent with objectives of an approach that considers all ecosystem consequences while managing fisheries. Balanced harvest is selective, but it broadens the selectivity perspective from scales of fishing operations and stocks to the integrated scale of ecosystem productivity and impacts.

Conventionally selective removal of parts of the ecosystem leads to unintended consequences that are inconsistent with a range of international conventions and agreements, including the international commitment to rebuild world fish stocks to their Maximum Sustainable Yield (MSY) $(29,30)$. It is increasingly recognized that all stocks within an ecosystem cannot be rebuilt to biomasses consistent with their single-species MSY levels (31). If the focus is on how much to fish as calculated from reducing fishing mortality $(1,2)$, MSY's dependence on what type of fishing is done-size-selectivity within stocks and species-selectivity at the community level (32)—is overlooked. Balanced harvesting requires adjusting selectivity regulations to balance the impact of all fisheries in an area with the relative productivities of the species and sizes of fish in the ecosystem; MSYs are subject to that constraint.

Regulations in many jurisdictions promote selectivity as an intended outcome, e.g., by using mesh size limits. Our results suggest that such regulations often will be inconsistent with goals to maintain biodiversity as well as fish yield. Implementing balanced harvesting requires coordinated management across multiple fisheries with consideration of ecosystem structure, consequences of current fishing selectivity, and implications for future yields. This involves quantifying patterns of fishing activities and ecological consequences aggregated at the fish-community and ecosystem levels.

We propose that fisheries management should address community properties such as the size-spectrum slope, for which acceptable levels would be agreed $(33,34)$. Ecosystem modeling could help in determining appropriate patterns of fishing mortality and selectivity, and constraints on removals (including discards), not just landings. Perhaps the greatest changes required for a balanced harvesting approach concern bycatch and markets. As each ecosystem component is to be caught in appropriate amounts, bycatch ceases to be an operational nuisance to be minimized, and becomes part of the management strategy. Markets and the processing sector will need incentives to accommodate a wider range of catch components, including many not currently utilized in Western countries but commonly used in multispecies, multigear fisheries $(6,35)$ in the Mediterranean, Asia, and the southern hemisphere: for example, (i) enhancing industrial processing for animal feed or human consumption (36), (ii) status change from bycatch to target (14), and (iii) consuming less-utilized fish species (37).

Issues regarding the potential benefits and implementation of balanced harvesting remain. However, consideration of food security and minimizing ecosystem impacts suggest that the time has come to take action.

\section{References and Notes}

1.E. K. Pikitch et al., Science 305, 346 (2004).

2.B. Worm et al., Science 325, 578 (2009).

3.S. M. Garcia, A. A. Rosenberg, Philos. Trans. R. Soc. London B Biol. Sci. 365, 2869 (2010). 
4.S. M. Garcia et al., Selective fishing and balanced harvest in relation to fisheries and ecosystem sustainability: Report of a scientific workshop in Nagoya, Japan, 14 to 16 October 2010 (IUCN and European Bureau for Conservation and Development, , Gland, Switzerland, and Brussels, 2011); http://data.iucn.org/dbtw-wpd/edocs/2011001.pdf.

5.O. A. Misund, J. Kolding, P. Fréon, in Handbook of Fish Biology and Fisheries, vol. 2, Fisheries P. J. B. Hart, J. D. Reynolds, Eds. (Blackwell, Malden, MA, 2002), pp. 13-36.

6.A. Bundy, P. Fanning, K. C. T. Zwanenburg, ICES J. Mar. Sci. 62, 503 (2005).

7.S. Zhou et al., Proc. Natl. Acad. Sci. U.S.A. 107, 9485 (2010).

8.Biological productivity is the amount of new organic matter produced per biomass unit during a given period of time.

9.R. G. Halliday, A. T. Pinhorn, Fish. Res. 57, 211 (2002).

10.R. J. H. Beverton, S. J. Holt, On the dynamics of exploited fish populations, Fishery Investigations, Series 2 (Her Majesty's Stationery Office, London, 1957).

11.M. P. Sissenwine, J. G. Shepherd, Can. J. Fish. Aquat. Sci. 44, 913 (1987).

12.R. L. Lewison, L. B. Crowder, A. J. Read, S. A. Freeman, Trends Ecol. Evol. 19, 598 (2004).

13.FAO, Report of the technical consultation to develop in-ternational guidelines on bycatch management and reduction of discards, Rome, 6 to 10 December 2010 (FAO Fisheries and Aquaculture Report No. 957, FAO, Rome, 2011).

14.S. J. Hall, B. M. Mainprize, Fish Fish. 6, 134 (2005).

15.S. J. Kennelly, M. K. Broadhurst, Fish Fish. 3, 340 (2002).

16.D. C. Dunn, A. M. Boustany, P. N. Halpin, Fish Fish. 12, 110 (2011).

17.C. Birkeland, P. K. Dayton, Trends Ecol. Evol. 20, 356 (2005).

18.C. N. Anderson et al., Nature 452, 835 (2008).

19.R. Law, ICES J. Mar. Sci. 57, 659 (2000).

20.C. Jørgensen et al., Science 318, 1247 (2007).

21.A. Kuparinen, J. Merilä, Trends Ecol. Evol. 22, 652 (2007).

22. N. Daan, H. Gislason, J. G. Pope, J. Rice, ICES J. Mar. Sci. 62, 177 (2005).

23. The size spectrum is the relative proportion of biomass per size-class in the fish community (see fig. S1). Increased spectrum slope reflects relative increase in biomass in smaller-size classes compared with larger classes.

24.E. Jul-Larsen, J. Kolding, J. R. Nielsen, R. Overa, P. A. M. van Zwieten, Management, co-management or no management? Major dilemmas in southern African freshwater fisheries (Tech. Rep. 426/1-2, FAO, Rome, 2003).

25.J. G. Pope, ICES Mar. Sci. Symp. 193, 22 (1991).

26.M.-J. Rochet, J. S. Collie, S. Jennings, S. J. Hall, Can. J. Fish. Aquat. Sci. 68, 469 (2011).

27.M.-J. Rochet, E. Benoît, Proc. Biol. Sci. 279, 284 (2012).

28.K. H. Andersen, M. Pedersen, Proc. Biol. Sci. 277, 795 (2010).

29. United Nations, Report of the World Summit on Sustainable Development, Johannesburg, South Africa, 26 August to 4 September 2002 (Tech. Report No.A/CONF.199/20*, United Nations, New York, 2002). 
30.MSY calculations assume that by applying a constant fishing mortality with a given selectivity (externally determined by fisheries), a constant yield can be taken from a stock over an indefinite period. There is one given fishing mortality rate that maximizes this yield, providing MSY.

31.M. N. Maunder, Fish Fish. 3, 251 (2002).

32.J. Link et al., Fish Fish. 12, 152 (2011).

33.Ecosystem level constraints on target species catch limits have been agreed, e.g., in the Antarctic ecosystem (34).

34.A. J. Constable et al., ICES J. Mar. Sci. 57, 778 (2000).

35.B. Gobert, Fish. Res. 19, 87 (1994).

36.I. Clucas, A study of the options for utilization of bycatch and discards from marine capture fisheries (FAO Fish. Circ., FAO, Rome, 1997).

37.Sainsbury's launches 'Switch the Fish' campaign, www.fishnewseu.com/latest-news/uk/5973-sainburys-launchesswitch-thefish-campaign.html.

38. This work results from a workshop sponsored by the International Union for the Conservation of Nature, the Convention on Biological Diversity, the Census of Marine Life, the Ministries of Fisheries and Coastal Affairs and of Foreign Affairs of Norway, the Global Guardian Trust of Japan, the Ocean Alliance of the University of Tokyo, the Japan National Association for the Conservation of Fishing Ground, the Japan Fisheries Association, and the Technical University of Denmark. M.-J.R. received support from The Pew Charitable Trusts. The opinions expressed are those of the authors and do not necessarily reflect the views of the supporting organizations. 


\section{Figures}
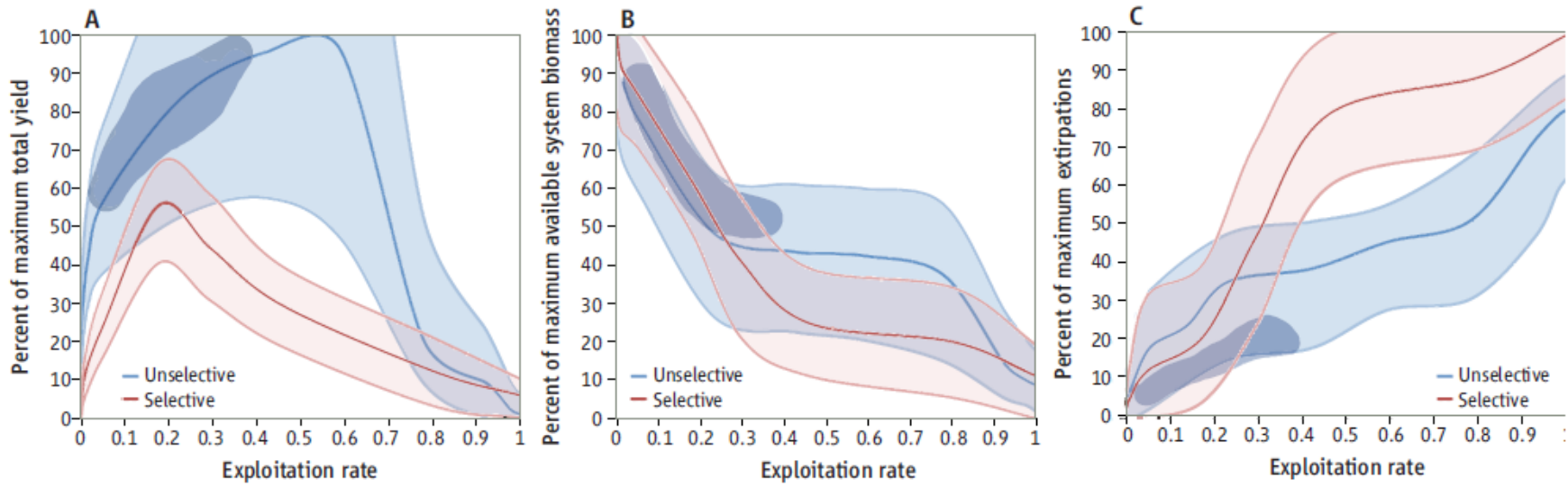

Fig. 1. Effects of conventionally selective (red), unselective (blue), and balanced (dark blue) fishing. Total catch weight (as a percentage of the maximum total yield for a system across all fishing scenarios) is plotted against system-level exploitation rate (roughly total catch as a proportion of total available biomass) across both conventionally selective and unselective fishing strategies. Unselective fishing harvests all exploitable nonmicrofauna and nonlarval ecosystem components. Balanced fishing mortality rates are set in proportion to productivity per biomass unit for each group. For each fishing type (conventionally selective or unselective), the solid line is the average across 36 ecosystem models, and the lower and upper bounds of the shaded areas represent the 5th and 95th percentiles across models. Dark blue shaded areas encompass $>90 \%$ of the balanced harvest scenarios across the models. See SOM for details. The selective fishing results were part of supplementary fig. S1 in (2).

\section{Supporting Online Material}




\section{Materials and Methods for Figure 1}

\section{Ecosystem models}

We compiled 36 published ecosystem models from 30 systems (Table S1). These models were either ECOPATH with ECOSIM (EwE) $(38,39)$ or ATLANTIS $(40)$ models. They were selected because they spanned systems with differing levels of productivity, degrees of environmental forcing (e.g., by upwellings), temperature profiles (primarily temperate and tropical), and levels of exploitation. In addition, the models were all publicly available, have been properly documented, have had their quality controlled, and have produced nonoscillatory results. [An additional model for Prince William Sound, Alaska (41), failed this last criterion and has not been included in this analysis.] For some models, multiple parameterizations existed; these models are marked with a “*” in Table S1. It was computationally impracticable to carry all parameterizations of every model through the whole analysis (as in some cases there were hundreds of parameterizations), so it was decided to use a subset of parameterizations. To select this subset, the parameterizations for each model were first scored (out of 5) against two criteria:

(i) simultaneous goodness of fit to multiple time series (a 5 was given if a parameterization provided a tight fit to multiple time series and spanned multiple functional groups or species, with lower scores given for less comprehensive fits or if fits were only achieved for a minority of groups in the model);

(ii) level of documentation within the model database on the source of the parameters and what motivated the alternative parameterization [a 5 was given if the parameterization was drawn from an alternative or extended data set for that system; a 3 if the parameterization was to cover uncertainty in a single data set (i.e., one parameterization covering upper bounds and another lower); and a 1 if it was purely hypothetical. A zero was given for no documentation].

Then, each parameterization was checked to see whether $100+$ year runs (with no fishing, historical levels of fishing, and 10×, 100×, and 1000× historical levels of fishing mortality) did not exhibit oscillations independent of any environmental forcing. Any parameterizations showing any numerical instability that was due to parameterization rather than external forcing was removed from the set to consider.

Finally, the four parameterizations for each model with the highest rank (i.e. closest to a total score of 10) that were also numerically stable were carried through the rest of the analysis. For those models where four or less alternative numerically stable parameter sets existed, all parameterization were run through the analysis detailed below. Note that, after the subsets were selected, the original authors of the models (marked with “\#” in Table S1) were contacted regarding which parameterizations they felt best represented their system and its function. In each case, the subset nominated by the original model developers and the subsets selected via the scoring method matched-which was taken as evidence that the selection method was robust. A full list of the scoring (a table would stretch for hundreds of pages) is available on request from the authors (Elizabeth Fulton, beth.fulton@csiro.au). 


\section{Note on fishing mortality}

Two types of measures of fishing mortality are used in the ecosystem modelling: fishing mortality and average exploitation rate. Instantaneous fishing mortality $F$ was applied to each species at the native time step of the model (from 12 hours in Atlantis to 1 month in EwE). For the purposes of Fig 1, we used the exploitation rate at the system level calculated as:

$$
U=\frac{\sum_{i} Y_{i}}{\sum_{i} \beta_{i}}
$$

where $Y_{i}$ is the average annual yield from species $i$ (averaged over the final 5 years of the simulation) and $\beta_{i}$ is the average (over the final 5 years of the simulation) of the standing biomass in the year plus any production in that year (i.e., due to individual growth plus recruitment). This summation of standing biomass plus production was taken as the annual estimate of total available biomass for the species (given that short-lived species can produce more than their standing biomass in a single year).

Alternative measures of system-level fishing pressure were found unsuitable for a variety of reasons, mostly to do with interpretability or translation into an index that could be feasibly calculated in reality (i.e., outside the models). For example, there is no straightforward equivalent to individual fishing mortality at a system level, and simply using an average (or median) value across species is also problematic because of the issue of how to weight the species included in the composite measure; at one extreme, a simple average increases the weight of species with little biomass to contribute; at the other extreme, if a weighted average was used, then effectively the most biomass-abundant groups dominate the signals.

\section{Analysis steps}

For each ecosystem model, we first identified fished groups. For the "conventionally selective fishing" case, this list consisted of all groups historically fished (including whaling, sealing, etc.) in a system-in the majority of cases, given the trophic resolution of the models, this meant simply using the list of groups with nonzero fishing mortalities. Where there were groups (particularly higher trophic levels) that may have been exploited in the past but weren't any longer (e.g., cetaceans and pinnipeds), first, the model documentation was checked (as this often stated whether a group was recovering from a depleted state); then, historical records were checked with the International Whaling Commission (IWC) report series (available from http://iwcoffice.org/); and where necessary, the original model authors were contacted for final confirmation of fishing history for the different model groups. For those models including age structure, only larger size classes (i.e., the marketable size and age classes observed in reality) were identified as "fishable" (i.e., would have fishing mortalities applied in the analysis steps detailed below). For lightly fished systems, where few groups had been fished historically, the list of groups and age classes that could be fished was expanded beyond what had been seen historically to include groups (and sizes) fished in heavily exploited systems of a similar type.

For the "unselective fishing," all nonmicrofauna that have been exploited somewhere in the world were included (e.g., jellyfish, macroalgae, and small-bodied pelagic 
invertebrate groups such as krill), as well as a broader set of size and age classes. That is, all post establishment size and age classes were marked as fishable, but any larval age classes listed in the EwE models and the very smallest age classes in Atlantis, which represent tiny settlers, were not identified as fishable unless fish of that size for that species or functional group had been recorded as fished somewhere in the world. Hence, the "unselective fishing" includes a wider range of species and size groups than the "selective fishing."

With the list of "fishable" groups identified for the selective and unselective fishing cases, the following steps were then carried out for each parameterization used for each ecosystem. Note that, although the analyses were done at one time, a nonnormalized form of the selective fishing scenario results have been presented previously in (figure S1of (2). Also, for the remainder of this description, please treat the word ecosystem as meaning a specific parameterization of an ecosystem model. Hence, in the production of the final Fig. 1, averaging, etc., was done treating each parameterization as an individual case. Although this handling does mean that some systems were represented up to four times and that those replicates did not have independent model structures, the different parameterizations lead to as much variance across outcomes for a single system as that seen between systems. Consequently, more complicated statistical handling was not undertaken, as the replicates did not introduce significant bias in the form of the overall outcomes (i.e., the normalized results for a single system did not all clump high or low compared with other ecosystems).

1) For each fished group in the model, we incrementally increased and decreased the fishing mortality rate $F_{i}$ (by 0.01 , with $F_{\min }=0$ and $F_{\max }=$ the $F$ that causes the biomass of the group to decline to zero), while holding $F$ constant for all other groups in the model, but allowing for full dynamic responses due to trophic interactions and direct fisheries extractions. This step produced an estimate of the fishing mortality that produced maximum sustainable yield $F_{\text {MSY,i }}$ for each fished group.

2) To allow for easy exploration of a wide range of fishing mortalities, the $F$ for the fished groups in the model was set to $k \times F_{\mathrm{MSY}, \mathrm{i}}$ from step 1 (where $k$ is a simple fishing mortality multiplier). Long-term runs (200-1000 years) were then run with $k$ increasing incrementally from $k=0$ (i.e., no fishing) to $k=20$ (which was sufficient to cause all groups to drop to extinction in the selective fishing case; in the case of the unselective fishing, it was necessary to take this to $k=100$ to reach the point where system-level annual removals reached $100 \%$ in all systems). For EwE, 1000 years was selected because these models are effectively equilibrium models, and the simulations had returned to a stable state (flat biomass trajectories through time) by 1000 years. Atlantis is not an equilibrium model and so never settles to one value-environmental variation from climate drivers interacting with ecological interactions means that there is always year-to-year variation, but under constant drivers (or repeating time series drawn from historical oceanographic observations), the biomass trajectories of the groups in the model do settle to vary within a band of values (with the very occasional rare event falling outside the band because of biophysical interactions); these bands are obvious if plotted as a time series or if maximum and minimum values are tracked over 5- to 10-year intervals through the course of a run. Initial investigatory runs showed that Atlantis runs settled into a band of values representative of their 1000 year state by 200 years. Consequently, given that Atlantis takes many days to run for 
such long simulation periods (versus a few minutes for EwE), the full set of runs were only run for 200 years each in Atlantis.

3) Although predation was allowed to vary during step 1 , in reality, $F$ would also vary across species through time (with changing targeting and gear use). Also, given that ecosystem interactions can be complex, it was necessary to do additional runs to try and further fill out the phase space of possible outcomes when fishing across an entire ecosystem. In other words, because of trophic and other interactions iterating $F_{\text {MSY }}$ across species does not cover a sufficiently large range of outcomes to paint a clear picture of even the general shape of ecosystem responses across a broad range of combinations of $F$ applied across species. Consequently, to complement the MSYbased exploration, we developed a wide range of alternative $F$ combinations by performing a set of fisheries policy searches using EwE to maximize a policy goal (represented by an objective function) - using the method detailed in the EwE user guide (available from http://www.ecopath.org/). The objective function used in the search combines economical, ecological, and potentially social terms. The set of searches was increased incrementally (in steps of 0.01) from the policy, with the economic contribution to the objective function set to 1 (effectively maximizing catch from the system, as there was little actual economic information included in the model formulations), and the ecological contribution (ecosystem structure and mandated rebuilding) set to 0 through to the opposite weightings (economic weighting $=0$, ecological $=1$ ).

To allow for representation of external pressure (or legal requirements) that force policy-makers to preserve or rebuild the population of a specific species, the objective function also includes a mandated rebuilding term (as described in the EwE user guide available from http://www.ecopath.org/). Rebuilding is not a universal requirement in all jurisdictions, but to facilitate a single analysis across all systems, a single rule was applied in all cases. In line with the majority of legal frameworks, harvest control rules, and fisheries science conventions on proxies for biomass supporting MSY versus unfished biomass (42), a mandated population size of $40 \%$ of unfished biomasses was chosen. In implementing these levels in the models, first, unfished levels needed to be determined. This was necessary because the base ECOPATH models did not represent unfished systems, and they included heavily exploited groups that were in an already depleted state, and so, simply setting rebuilding to 0.4 of ECOPATH values would be inappropriate. To find unfished levels, a long-term run of each ECOSIM model was done with all fishing mortality rates set to 0 . Then, within the optimizations, the levels of mandated rebuilding from base ECOPATH levels were set according to how the base ECOPATH model biomasses compared with $40 \%$ of the unfished biomass levels.

Ideally social (employment) considerations would have also been included in this policy search. Unfortunately, employment information was not readily available for many of the modelled fleets, and the same fleet resolution was not available in all models, so social contributions to the objective function were not considered. Run times precluded also doing an optimality search directly with Atlantis. Consequently, the search was only run in EwE, and then, the fishing mortalities per group were applied in both models (EwE and Atlantis) to check for consistency in outcome across the models. 
4) The results from the different analyses per system (i.e., the results of steps 2 and 3 for each parameterization of each model) were then combined (i.e., all simulations were plotted on the same plot) to produce aggregate plots of catch, available biomass (both standing stock and production in the year), and the number of groups that have dropped below $10 \%$ of their unfished levels (defined as "extirpated") against the system-level exploitation rate.

Finally, the overall plot comparing the selective and unselective cases (Fig. 1) was created by (i) normalizing the results for the system in step 4 relative to the maximum value observed across the two fishing cases (selective and unselective) for each metric (catch, biomass, and extirpations) in any simulation for that system (regardless of the kind of fishing used) and then (ii) combining all of the normalized results (i.e., across all parameterizations of all the systems) on a single plot. The solid line (in Fig. 1) marks the average across all ecosystems (and parameterizations) per fishing type (selective or unselective), and the confidence bounds mark the 5th and 95th percentiles across all ecosystems (and parameterizations), as generated by combining uncertainties from the various ecosystems (and parameterizations) by using standard error propagation methods (43).

With respect to the modelling, balanced harvesting scenarios were defined as those scenarios where all nonmicrofauna (and postlarval stages, see the definition of unselective scenarios at the start of this section) in a system are harvested in proportion to their productivity per unit of biomass (i.e., those fishing mortality scenarios produced in the steps outlined above that had a distribution of relative fishing mortalities that matched the distribution of relative productivity across all fished species were tagged as being a case of "balanced harvesting"). Although the identity and results of these scenarios was tracked through the analysis process, instead of individually marking them on Fig. 1 (which would make it difficult to read), the area encompassing the majority (over 90\%) of these scenarios across the systems and parameterizations is marked in dark blue in Fig. 1. There is no pattern to the remainder of the cases except (i) none fall below the 5th percentile for total yield or available biomass and (ii) all but two are below the mean number of extirpations for selective fishing, and even those two are below the mean for unselective fishing.

The full set of results is available on request from the authors (Elizabeth Fulton, beth.fulton@csiro.au)

\section{Acknowledgments}

We are grateful to those colleagues who provided access to information on ecosystem models they had developed. In particular we would like to recognize the models contributed by C. Ainsworth, A. Bundy, J. Fields, I. Kaplan, J. Link, J. Little, C. Bulman, N.Gribble, and S. Mackinson. 


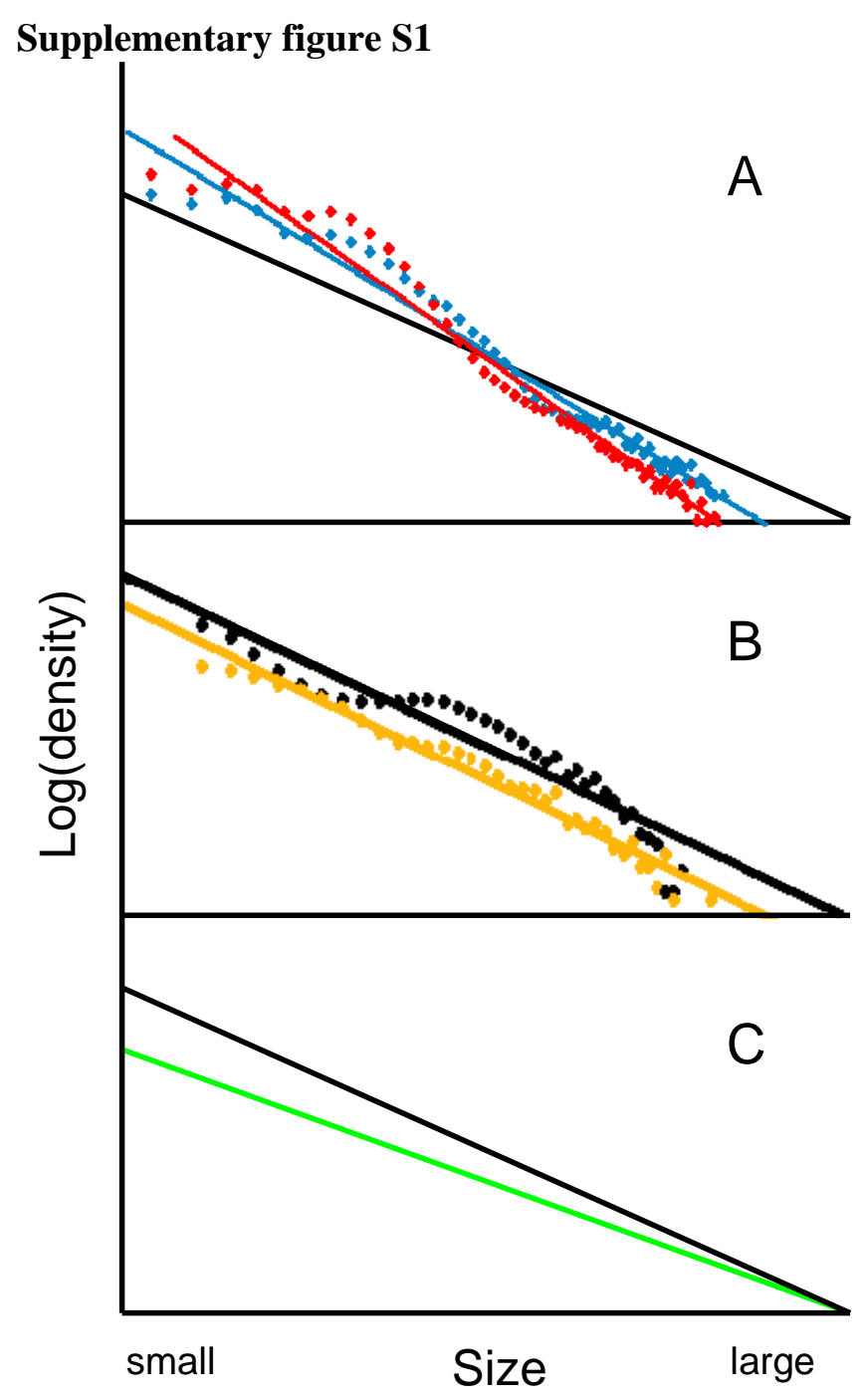

Fig. S1. The different community size spectra resulting from alternative harvesting strategies. Black lines/symbols are before fishing, colored lines/symbols are after fishing. (A) Conventional selective fishing: North Sea before fishing ${ }^{1}$ and from two later periods, 1983-1987 (blue symbols and regression line), and after more accumulated fishing impact 1998-2002 (red symbols and regression line). (B) Unregulated weakly selective fishing: Lake Kariba, Africa, from an unfished (black symbols and regression line) and a heavily fished area (yellow symbols and regression line). (C) Conceptual model of balanced harvest (green line) with exploitation proportional to natural productivity (black line); we are not aware of an empirical example for this strategy.

\footnotetext{
${ }^{1}$ The unfished line for the North Sea (A) is hypothetical based on (64) and data are numbers per $\mathrm{km}^{2}$ from the North Sea International Bottom Trawl Survey (65), extracted from ICES online trawl survey database http://datras.ices.dk/Home/Default.aspx. Data from Lake Kariba (B) are all numbers per 45-m net set of experimental gillnets averaged over 1980 to 1994 [see (66) for details]. Size is binned to 2cm-length groups.
} 


\section{Supporting Table}

Table S1. List of 36 ecosystem models for 30 systems and their sources used to explore multispecies MSY. For some systems, two EwE models from different time periods were used. Those with a * had multiple parameterizations included in the analysis. Authors of the models marked with “\#”were contacted regarding which parameterizations they felt best represented their system and its function. In each case, the subset nominated by the original model developers and the subsets selected via the scoring method described earlier matched - which was taken as evidence that the selection method was robust.

\begin{tabular}{lll}
\hline System & Model type & Notes and Source(s) \\
\hline Aleutians & EwE & $(44)$ \\
Australia Darwin Harbour & EwE & $(45)$ \\
Baltic & EwE & Database for (46) \\
Bay of Biscay & EwE & $(47)$ \\
Benguela*\# & 2 EwE & Database for (46) \\
Black Sea & EwE & Database for (46) \\
California Current*\# & 2 EwE and 1 Atlantis & $(48,49)$ \\
Canada - Nth Gulf St Lawrence & EwE & $(50)$ \\
Central Nth Pacific & EwE & Database for (46) \\
Chesapeake* & EwE & Database for (46) \\
Eastern Bering Sea & EwE & Database for (46) \\
Eastern Tropical Pacific & EwE & Database for (46) \\
Great Barrier Reef*\# & EwE & $(51)$ \\
Georges Bank & EwE & $(52)$ \\
Georgia Strait & EwE & Database for (46) \\
Gironde Estuary & EwE & $(53)$ \\
Grand Banks & EwE & $(54)$ \\
Gulf Mexico* & EwE & $(55)$ \\
Gulf Thailand 1973 & EwE & Database for (46) \\
Irish Sea & EwE & $(56)$ \\
New Zealand & EwE & $(57)$ \\
North Sea* & EwE & Database for (46), (58) \\
North West Shelf*\# & EwE & $(59)$ \\
Port Phillip Bay*\# & EwE & $(60)$ \\
SE Alaska 1963 & EwE & $(44)$ \\
SE Australia*\# & 2 EwE and 1 Atlantis & $(61)$ \\
Tampa Bay & EwE & Database for (46) \\
West Coast Vancouver Island & EwE & Database for (46) \\
Western English Channel* & 2 EwE & $(62)$ \\
West Florida Shelf & EwE & $(63)$ \\
\hline & & \\
\hline
\end{tabular}




\section{References and Notes}

1. E. K. Pikitch et al., Ecosystem-based fishery management. Science 305, 346 (2004). doi:10.1126/science.1098222 Medline

2. B. Worm et al., Rebuilding global fisheries. Science 325, 578 (2009).

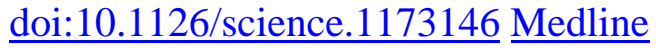

3. S. M. Garcia, A. A. Rosenberg, Food security and marine capture fisheries: Characteristics, trends, drivers and future perspectives. Philos. Trans. R. Soc. London Ser. B 365, 2869 (2010). doi:10.1098/rstb.2010.0171 Medline

4. S. M. Garcia et al., Selective fishing and balanced harvest in relation to fisheries and ecosystem sustainability: Report of a scientific workshop in Nagoya, Japan, 14 to 16 October 2010 (IUCN and European Bureau for Conservation and Development, Gland, Switzerland, and Brussels, 2011); http://data.iucn.org/dbtwwpd/edocs/2011-001.pdf.

5. O. A. Misund, J. Kolding, P. Fréon, in Handbook of Fish Biology and Fisheries, vol. 2, Fisheries P. J. B. Hart, J. D. Reynolds, Eds. (Blackwell, Malden, MA, 2002), pp. 13-36.

6. A. Bundy, P. Fanning, K. C. T. Zwanenburg, Balancing exploitation and conservation of the eastern Scotian Shelf ecosystem: Application of a 4D ecosystem exploitation index. ICES J. Mar. Sci. 62, 503 (2005). doi:10.1016/j.icesjms.2004.12.008

7. S. Zhou et al., Ecosystem-based fisheries management requires a change to the selective fishing philosophy. Proc. Natl. Acad. Sci. U.S.A. 107, 9485 (2010). doi:10.1073/pnas.0912771107 Medline

8. Biological productivity is the amount of new organic matter produced per biomass unit during a given period of time.

9. R. G. Halliday, A. T. Pinhorn, A review of the scientific and technical bases for policies on the capture of small fish in North Atlantic groundfish fisheries. Fish. Res. 57, 211 (2002). doi:10.1016/S0165-7836(02)00079-6

10. R. J. H. Beverton, S. J. Holt, On the dynamics of exploited fish populations, (Fishery Investigations, Series 2, Her Majesty's Stationery Office, London, 1957).

11. M. P. Sissenwine, J. G. Shepherd, An Alternative Perspective on Recruitment Overfishing and Biological Reference Points. Can. J. Fish. Aquat. Sci. 44, 913 (1987). doi:10.1139/f87-110

12. R. L. Lewison, L. B. Crowder, A. J. Read, S. A. Freeman, Understanding impacts of fisheries bycatch on marine megafauna. Trends Ecol. Evol. 19, 598 (2004). doi:10.1016/j.tree.2004.09.004

13. FAO, Report of the technical consultation to develop international guidelines on bycatch management and reduction of discards, Rome, 6 to 10 December 2010 (FAO Fisheries and Aquaculture Report No. 957, FAO, Rome, 2011). 
14. S. J. Hall, B. M. Mainprize, Managing by-catch and discards: How much progress are we making and how can we do better? Fish Fish. 6, 134 (2005). doi:10.1111/j.1467-2979.2005.00183.x

15. S. J. Kennelly, M. K. Broadhurst, By-catch begone: Changes in the philosophy of fishing technology. Fish Fish. 3, 340 (2002). doi:10.1046/j.14672979.2002.00090.x

16. D. C. Dunn, A. M. Boustany, P. N. Halpin, Spatio-temporal management of fisheries to reduce by-catch and increase fishing selectivity. Fish Fish. 12, 110 (2011). doi:10.1111/j.1467-2979.2010.00388.x

17. C. Birkeland, P. K. Dayton, The importance in fishery management of leaving the big ones. Trends Ecol. Evol. 20, 356 (2005). doi:10.1016/j.tree.2005.03.015 Medline

18. C. N. Anderson et al., Why fishing magnifies fluctuations in fish abundance. Nature 452, 835 (2008). doi:10.1038/nature06851 Medline

19. R. Law, Fishing, selection, and phenotypic evolution. ICES J. Mar. Sci. 57, 659 (2000). doi:10.1006/jmsc.2000.0731

20. C. Jørgensen et al., Managing evolving fish stocks. Science 318, 1247 (2007). doi:10.1126/science.1148089 Medline

21. A. Kuparinen, J. Merilä, Detecting and managing fisheries-induced evolution. Trends Ecol. Evol. 22, 652 (2007). doi:10.1016/j.tree.2007.08.011 Medline

22. N. Daan, H. Gislason, J. G. Pope, J. C. Rice, Changes in the North Sea fish community: Evidence of indirect effects of fishing? ICES J. Mar. Sci. 62, 177 (2005). doi:10.1016/j.icesjms.2004.08.020

23. The size spectrum is the relative proportion of biomass per size-class in the fish community (see Fig. S1). Increased spectrum slope reflects relative increase in biomass in smaller-size classes compared with larger classes.

24. E. Jul-Larsen, J. Kolding, J. R. Nielsen, R. Overa, P. A. M. van Zwieten, Management, co-management or no management? Major dilemmas in southern African freshwater fisheries (Tech. Rep. 426/1-2, FAO, Rome, 2003).

25. J. G. Pope, ICES Mar. Sci. Symp. 193, 22 (1991).

26. M.-J. Rochet, J. S. Collie, S. Jennings, S. J. Hall, Does selective fishing conserve community biodiversity? Predictions from a length-based multispecies model. Can. J. Fish. Aquat. Sci. 68, 469 (2011). doi:10.1139/F10-159

27. M.-J. Rochet, E. Benoît, Fishing destabilizes the biomass flow in the marine size spectrum. Proc. Biol. Sci. 279, 284 (2012). doi:10.1098/rspb.2011.0893 Medline

28. K. H. Andersen, M. Pedersen, Damped trophic cascades driven by fishing in model marine ecosystems. Proc. Biol. Sci. 277, 795 (2010). doi:10.1098/rspb.2009.1512 Medline

29. United Nations, Report of the World Summit on Sustainable Development, Johannesburg, South Africa, 26 August to 4 September 2002 (Tech. Report No.A/CONF.199/20*, United Nations, New York, 2002). 
30. MSY calculations assume that, by applying a constant fishing mortality with a given selectivity (externally determined by fisheries), a constant yield can be taken from a stock over an indefinite period. There is one given fishing mortality rate that maximizes this yield, providing MSY.

31. M. N. Maunder, The relationship between fishing methods, fisheries management and the estimation of maximum sustainable yield. Fish Fish. 3, 251 (2002). doi:10.1046/j.1467-2979.2002.00089.x

32. J. Link et al., Ecosystem-based fisheries management in the Northwest Atlantic. Fish Fish. 12, 152 (2011). doi:10.1111/j.1467-2979.2011.00411.x

33. Ecosystem level constraints on target species catch limits have been agreed, e.g., in the Antarctic ecosystem (34).

34. A. J. Constable et al., Managing fisheries to conserve the Antarctic marine ecosystem: Practical implementation of the Convention on the Conservation of Antarctic Marine Living Resources (CCAMLR). ICES J. Mar. Sci. 57, 778 (2000). doi:10.1006/jmsc.2000.0725

35. B. Gobert, Size structures of demersal catches in a multispecies multigear tropical fishery. Fish. Res. 19, 87 (1994). doi:10.1016/0165-7836(94)90016-7

36. I. Clucas, A study of the options for utilization of bycatch and discards from marine capture fisheries (FAO Fish. Circ., FAO, Rome, 1997).

37. Sainsbury's launches 'Switch the Fish' campaign, www.fishnewseu.com/latestnews/uk/5973-sainburys-launches-switch-thefish-campaign.html

38. C. J. Walters, V. Christensen, D. Pauly, Rev. Fish Biol. Fish. 7, 139 (1997). doi:10.1023/A:1018479526149

39. V. Christensen, C. Walters, Ecopath with Ecosim: Methods, capabilities and limitations. Ecol. Modell. 172, 109 (2004). doi:10.1016/j.ecolmodel.2003.09.003

40. E. A. Fulton, A. D. M. Smith, A. E. Punt, Which ecological indicators can robustly detect effects of fishing? ICES J. Mar. Sci. 62, 540 (2005). doi:10.1016/j.icesjms.2004.12.012

41. T. A. Okey, D. Pauly, A Trophic Mass Balance Model of Alaska's Prince William Sound Ecosystem for the Post-Spill Period 1994-1996 [Fisheries Centre Research Report 7(4),Univ. of British Columbia, Vancouver, ed. 2, 1999].

42. A. E. Punt, M. W. Dorn, M. A. Haltuch, Evaluation of threshold management strategies for groundfish off the U.S. West Coast. Fish. Res. 94, 251 (2008).

43. S. L. Meyer, Data Analysis for Scientists and Engineers (Wiley, New York, 1975).

44. S. Guénette, S. J. J. Heymans, V. Christensen, A. W. Tries, Ecosystem models show combined effects of fishing, predation, competition, and ocean productivity on Steller sea lions (Eumetopias jubatus ) in Alaska. Can. J. Fish. Aquat. Sci. 63, 2495 (2006). doi:10.1139/f06-136

45. J. M. Martin, The distribution, abundance and trophic ecology of the fishes of Darwin harbour mangrove habitats, thesis, Charles Darwin University (2005). 
46. C. Walters, V. Christensen, S. J. D. Martell, J. F. Kitchell, Possible ecosystem impacts of applying MSY policies from single-species assessment. ICES J. Mar. Sci. 62, 558 (2005). doi:10.1016/j.icesjms.2004.12.005

47. C. Ainsworth, B. Ferriss, E. Leblond, S. Guénette, in Fisheries Impacts on North Atlantic Ecosystems: Models and Analyses, S. Guénette, V. Christensen, D. Pauly, Eds. (Fisheries Centre, Univ. of British Columbia, Vancouver, 2001), pp. 271313.

48. J. C. Field, R. C. Francis, K. Aydin, Top-down modeling and bottom-up dynamics: Linking a fisheries-based ecosystem model with climate hypotheses in the Northern California Current. Prog. Oceanogr. 68, 238 (2006). doi:10.1016/j.pocean.2006.02.010

49. E. J. Brand et al., A Spatially Explicit Ecosystem Model of the California Current's Food Web and Oceanography (NWFSC Technical Memorandum, NOAA, Seattle, 2007).

50. L. Morissette et al., Can. Tech. Rep. Fish. Aquat. Sci. 2497, 94 (2003).

51. N. A. Gribble, in 18th World IMACS Congress and MODSIM09 International Congress on Modelling and Simulation: Interfacing Modelling and Simulation with Mathematical and Computational Sciences, R. S. Anderssen, R. D. Braddock, L. T. H. Newham, Eds. (Univ. of Western Australia, Nedlands, Western Australia, 2009), pp. 2115-2121.

52. J. Link et al., The northeast U.S. continental shelf Energy Modeling and Analysis exercise (EMAX): Ecological network model development and basic ecosystem metrics. J. Mar. Syst. 74, 453 (2008). doi:10.1016/j.jmarsys.2008.03.007

53. J. Lobry, Which reference pattern of functioning for estuarine ecosystems? The case of fish successions in the Gironde estuary (French Institute of Agricultural and Environmental Engineering Research, Castas, France, 2004).

54. A. Bundy, G. Lilly, P. Shelton, A mass balance model of the Newfoundland-Labrador shelf . Can. Tech. Rep. Fish. Aquat. Sci. 2310 (2000).

55. C. Walters, S. J. D. Martell, V. Christensen, B. Mahmoudi, Bull. Mar. Sci. 83, 251 (2008).

56. K. Lees, S. Mackinson, An Ecopath model of the Irish Sea: Ecosystems properties and sensitivity analysis. [Science Series Tech. Rep. 138, Centre for Environment, Fisheries, and Aquaculture Science (CEFAS), Lowestoft, 2007].

57. J. M. Bradford-Grieve et al., Pilot trophic model for subantarctic water over the Southern Plateau, New Zealand: A low biomass, high transfer efficiency system. J. Exp. Mar. Biol. Ecol. 289, 223 (2003). doi:10.1016/S0022-0981(03)00045-5

58. S. Mackinson, G. Daskalov, An ecosystem model of the North Sea for use in research supporting the ecosystem approach to fisheries management: Description and parameterization (Science Series Tech. Rep. 148, CEFAS, Lowestoft, 2007). 
59. C. Bulman, Trophic webs and modelling of Australia's North West Shelf [Commonwealth Scientific and Industrial Research Organization (Australia) (CSIRO) Marine and Atmospheric Research, Hobart, Australia, 2006].

60. E. A. Fulton, A. D. M. Smith, Lessons learnt from a comparison of three ecosystem models for Port Phillip Bay, Australia. Afr. J. Mar. Sci. 26, 219 (2004). doi:10.2989/18142320409504059

61. C. Bulman et al., Trophic dynamics of the eastern shelf and slope of the south east fishery: impacts of and on the fishery (Final Report for Fisheries Research and Development Corporation, Project 2002/028, CSIRO, Hobart, Australia, 2006).

62. J. N. Araújo et al., Modelling food web interactions, variation in plankton production, and fisheries in the western English Channel ecosystem. Mar. Ecol. Prog. Ser. 309, 175 (2006). doi:10.3354/meps309175

63. T. A. Okey et al., Simulating community effects of sea floor shading by plankton blooms over the West Florida Shelf. Ecol. Modell. 172, 339 (2004). doi:10.1016/j.ecolmodel.2003.09.015

64. International Council for the Exploration of the Sea (ICES), Manual for the International Bottom Trawl Surveys. Addendum to ICES C.M. 1996/H: 1 (ICES, Copenhagen, 1996).

65. S. Jennings, J. L. Blanchard, Fish abundance with no fishing: Predictions based on macroecological theory. J. Anim. Ecol. 73, 632 (2004). doi:10.1111/j.00218790.2004.00839.x

66. E. Jul-Larsen, J. Kolding, J. R. Nielsen, R. Overa, P. A. M. van Zwieten, Management, co-management or no management? Major dilemmas in southern African freshwater fisheries. (Tech. Rep. 426/1-2, FAO, Rome. 2003). 